\title{
KONDISI DAN JENIS MANGROVE DI KABUPATEN MERAUKE, PROVINSI PAPUA
}

\author{
Siti masiyah*, Taslim Arifin** \\ *Staf Pengajar FAPERTA UNIMUS-Merauke,e-mail: masiyah@yahoo.com \\ **Staf Badan Riset, SDM Kelautan dan KKP, e-mail: -
}

\begin{abstract}
ABSTRAK
Penelitian ini dilakukan untuk mengidentifikasi mangrove serta mengetahui indeks nilai penting (INP) mangrove di Kabupaten Merauke. Indeks Nilai Penting (INP) ini digunakan untuk menetapkan dominasi suatu jenis terhadap jenis lainnya atau dengan kata lain. Indeks Nilai Penting dalam penelitian ini dihitung berdasarkan penjumlahan nilai Kerapatan Relatif (KR), Frekuensi Relatif (FR) dan Luas penutupan relatif(CR). Hasil penelitian didapatkan jumlah jenis mangrove 8 jenis mangrove pada Distrik Naukenjerai antara lain Avicennia alba, A. Eucalyptifolia, Aegialitis annulata, Aegliceras floridum, Brugueira cylindrica, Acanthus ilicifolus, Sonneratia alba dan R. mukronata dengan jenis mangrove Avicennia sp lebih dominan, Distrik payum 11 jenis mangrove antara lain Avicennia. Alba, A. Eucalyptifolia, Aegialitis annulata, Aegiceras corniculatum, Aegliceras floridum, Acanthus abractearus, Brugueira cylindrica, Acanthus ilicifolus, R. mukronata, R. stylosa, dan Sonneratia alba dengan jenis Avicennia sp lebih dominan sedangkan Distrik Kumbe didapatkan 13 jenis mangrove antara lain Avicennia. Alba, A. Eucalyptifolia, Aegialitis annulata, Aegliceras floridum, Brugueira cylindrica, Acanthus ilicifolus, B. Gymnorhiza, B. Hainessii, Ceriop decandra, Bruguiera sexangula, R. Mukronata, R. Stylosa, dan Sonneratia alba dengan jenis mangrove Rhizophora sp lebih melimpah daripada yang lain. Hasil analisis Indek Nilai Penting penting mangrove pada stasiun I Kampung Nasem berkisar antara $300 \%$ - 15\% masuk dalam kategori tinggi. Pada Stasiun II Distrik Payum nilai INP berkisar antara $260 \%$ - $27 \%$ memiliki nilai kategori tinggi sedangkan untuk stasiun III Distrik Kumbe nilai INP berkisar antara235\% - 18\%. Juga masuk kategori INP tinggi. Penelitian dengan tujuan untuk mengetahui identifikasi dan indeks nilai penting mangrove di Kabupaten Merauke.
\end{abstract}

Kata Kunci: Identifikasi, Indek, Nilai, Penting, Merauke,Provinsi, Papua.

\section{PENDAHULUAN}

Kabupaten Merauke memiliki potensi sumberdaya alam yang sangat luas, baik baik potensi sumberdaya yang dalam proses pemanfaatan maupun potensi untuk pengembangan sumberdaya alam. Potensi sumber daya alam di Kabupaten Merauke sangat tinggi dan beranekaragam, baik potensi SDA Hutan, SDA Sungai, SDA Pantai, dan SDA Laut. Daerah ini terdiri dari perairan laut Arafura sekitar $75.000 \mathrm{~km}^{2}$, perairan umum (sungai dan rawa) sekitar $71.000 \mathrm{~km}^{2}$ dan garis pantai $1.050 \mathrm{~km}^{2}$ yang membentang dari Sungai
Torasi diperbatasan Republik Indonesia dan Papua New Guenia, disebelah Timur sampai pada Sungai Syrest (Data Badan Pusat Statistik Kabupaten Merauke, 2011). Merauke yang terletak di ujung selatan Papua memiliki ekosistem mangrove yang sangat luas. Menurut data yang dirilis oleh Pemerintah Kabupaten Merauke Tahun 2009, Kabupaten Merauke memiliki luasan hutan mangrove. 4.672,382 Ha.

Ekosistem mangrove sering disebut sebagai hutan payau atau hutan bakau. hutan mangrove adalah tipe hutan yang khas terdapat 
disepanjang pantai atau muara sungai yang masih dipengaruhi oleh pasang surut air laut (Nontji, 2007). Hutan mangrove mempunyai peranan yang sangat penting, baik dari segi ekologi dan biologi untuk menunjang kelangsungan berbagai jenis-jenis hewan yang hidup didalamnya. Misalnya ekosistem ini berperan sebagai habitat untuk berbagai jenis ikan-ikan, crustacean dan molusca. Sehingga dikatakan hutan mangrove merupakan ekosistem kunci dan ekosistem penunjang utama kawasan pesisir laut Arafura. Penelitian ini sangat penting untuk konservasi dan vitalisasi ekosistem mangrove sebagai ekosistem kunci dan penunjang keseimbangan kawasan pesisir laut Arafura.

Ekosistem mangrove yang memiliki fungsi yang sangat tinggi, baik fungsi secara biologi, ekologi maupun ekonomi menjadikan mangrove sebagai ekosistem yang rentan terhadap kerusakan. Potensi mangrove yang tinggi di Kabupaten Merauke baik secara ekologi berhadapan dengan sungai, maupun laut masih sangat sedikit dilakukan penelitian. Untuk potensi mengrove pada ekosistem sungai di Kabupaten Merauke belum pernah dilakukan. Sedangkan mangrove pada pesisir atau daerah yang berhadapan langsung dengan laut pernah dilakukan oleh Masiyah siti (2014) yang dilakukan di pesisir Arafura dengan mengambil tiga titik di Payum, Lampu satu dan Karang Indah yang kesemuanya terletak pada Distrik Merauke.

Potensi mangrove pada penelitian ini meliputi Identifikasi mangrove, indeks nilai penting dan kondisi mangrove di Kabupaten Merauke. Adapun tujuan dari penelitian ini antara lain: ( 1) untuk mengetahui identifikasi mangrove di Kabupaten Merauke dengan mengambil tiga Distri yaiu Distrik Merauke, Distrik Naukenjerai dan Distrik semangga.( 2) mengetahui potensi mangrove dengan menggunakan analisis Indeks Nilai Penting (INP) dari masing- masing Distrik.

\section{METODE PENELITIAN}

\subsection{Waktu dan Tempat}

Penelitian dilakukan di Kabupaten Merauke, tepatnya di 3 Distrik yaitu Distrik Merauke, Distrik Semangga dan Distrik Naukenjerai. Untuk Distrik Merauke sampling diambil pada Kampung Payum, Distrik Naukenjerai sampling dilakukan pada Kampung Nasim dan Distrik Semangga pada Kampung Kumbe. Penelitian dilakukan selama bulan Oktober 2015 yang dilakukan bersama dengan Team Musamus dan Kementerian Kelautan Perikanan.

\subsection{Metode Penelitian}

Kegiatan yang dilakukan di Kabupaten Merauke dengan mengambil data primer dan data sekunder. Pengembilan data Primer mencakup Identifikasi mangrove, pengukuran diameter pohon mangrove yang akan digunakan untuk analisis kerapatan Jenis relatif, frekuensi Jenis rekatif, dan luas penutupan jenis relatif.

Adapun prosedur pengamatan dan pengambilan data mangrove yaitu:

(1). Membuat petak contoh (plot) i transek quadran dengan bentuk bujur sangkar ukuran luas $10 \times 10 \mathrm{~m}$, dengan jumlah plot sebanyak 6 unit.

(2). Mengidentifikasi nama jenis-jenis tumbuhan mangrove yang belum diketahui dengan cara mengambil sebagian/potongan dari ranting, lengkap dengan bunga dan daunnya.

(3). Menghitung jumlah spesies mangrove, jumlah anakan, mengukur diameter batang pohon mengrove.

(4). Melakukan pengukuran lingkar pohon mangrov eyang akan digunakan untuk analisis Indeks Nilai Penting (INP) mangrove.

\subsection{Analisis Data}

Data yang dikumpulkan meliputi : data mengenai spesies, jumlah individu, dan diameter pohon yang telah dicatat pada form mangrove, kemudian diolah untuk memperoleh kerapatan spesies, frekuensi spesies, luas areal tutupan, nilai penting suatu spesies, frekuensi spesies, luas areal tutupan, nilai penting suatu spesies dan keanekaragaman spesies (Bengen, 2004):

Kerapatan Jenis

$$
\mathrm{Di}=\frac{n i}{A}
$$

Keterangan :

$$
\mathrm{Di}=\text { Kerapatan jenis }\left(\mathrm{ind} / \mathrm{m}^{2}\right)
$$


ni $=$ Jumlah total tegakan jenis $\mathbf{i}$

A = Luas total area pengambilan contoh

Kerapatan Relatif Jenis

$$
\text { Rdi }=\frac{n i}{\sum n} x 100 \%
$$

Keterangan :

Rdi = Kerapatan relatif penting (\%)

ni $=$ Jumlah total tegakan jenis $\mathrm{i}$

n = Jumlah total tegakan seluruh jenis

Frekuensi Jenis

$$
\mathbf{F i}=\frac{p i}{\sum p}
$$

Keterangan :

Fi $=$ Frekuensi jenis

$\mathbf{P i}=$ Jumlah petak contoh ditemukan jenis $\mathbf{i}$

$\mathrm{p}=$ Jumlah total petak contoh yang diamati

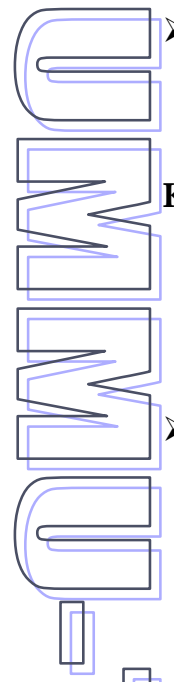

Frekuensi Relatif Jenis

$$
\text { Rfi }=\frac{F i}{\sum F} x 100 \%
$$

Keterangan :

Rfi $=$ Frekuensi relatif jenis

Fi = Frekuensi jenis

F $\quad$ Jumlah Frekuensi

Penutupan Jenis

$$
\begin{aligned}
& \mathrm{C} \mathbf{i}=\frac{\sum B A}{A} ; \operatorname{dimana} \quad \mathbf{B A}=\frac{\pi D B H^{2}}{4} ; \\
& \text { dimana } \mathrm{DBH}=\frac{C B H}{\pi}
\end{aligned}
$$

Keterangan :

$\mathrm{Ci}=$ Penutupan Jenis, BA (dalam $\left.\mathrm{cm}^{2}\right)$

$\mathrm{DBH}=$ Diameter pohon jenis $\mathrm{i}(\mathrm{cm})$

$\pi \quad=$ Konstanta $(3,1416)$.

$\mathrm{CBH}=$ Lingkaran pohon setinggi dada.

Penutupan Relatif Jenis

$$
\text { Rci }=\frac{C i}{\sum C} \times 100 \%
$$

Keterangan :
$\mathbf{C} \mathbf{i}=$ Luas area penutupan jenis $\mathbf{i}$
$\mathrm{C}=$ Luas total area untuk seluruh jenis

Indeks nilai penting

$\mathrm{INP}=\mathrm{RDi}+\mathrm{RFi}+\mathrm{Rci}$

\section{IIL. DAN PEMBAHASAN}

\subsection{Identifikasi Mangrove}

Hasil identifikasi mangrove di Kabupaten Merauke pada masing-masing Distrik tidak sama, untuk lebih jelasnya hasil identifikasi mangrove dapat dilihat pada Tabel. 1.

Hasil Identifikasi mangrove dari ketiga stasiun berbeda, pada stasiun 1 ( Kampung Nasem) mangrove yang memiliki luas $1,2 \mathrm{ha}$ ini didapatkan 8 jenis mangrove. Dari 8 spesies tersebut banyak di dominasi oleh jenis Avicennia alba, hal ini dikarenakan substrat yang sesuai dengan kelangsungan hidup Avicennia $s p$ selain itu, secara langsung ekosistem mangrove yang ada di Kampung Nasem terletak berhadapan langsung dengan laut. Hasil dari survei Avicennia $S p$ yang masih alami terbentuk kawasan tersendiri dimana daerah sampling II terdapat hampir $\mathbf{9 0} \%$ jenis Avicennia sp, terdapat juga Sonneratia, Rhizophora hanya sebagian kecil. Begitu juga dengan daerah sampling II ekosistem mangrove masih banyak didapatkan Avicennia $s p$ dan beberapa jenis Sonneratia, Rhizophora, Aegialitis annulata, Aegliceras floridum yang hanya sebagian kecil. Didapatkan juga jenis Rhizophora pada daerah Sampling II dimana daerah ekosistem mangrove disini terdapat anakan sungai, secara ekologi mangrove Rhizophora akan tubuh subur dengan baik dengan susbtrat yang liatnya/lumpurnya lebih besar dan salinitas garam yang tidak terlalu tinggi. Hasil keseluruhan pada Kampung Nasem mangrove jenis Avicennia sp, memiliki jumlah yang sangat besar, kemudian Rhizophora sp, dan Sonneratia sp.

Hasil penelitian pada stasiun II (Kampung Payum) yang memiliki daerah sangat luas, hasil identifikasi mangrove didapatkan 11 jenis mangrove. Secara ekologi ekosistem mangrove yang terdapat pada Kampung Payum sangat bervariasi, dimana daerah yang dekat sekali dengan daratan, terdapat anakan sungan yang besar selain itu berhadapan langsung dengan laut. Kelimpahan mangrove dari beberapa jenis sangat tinggi, artinya zonasi mangrove sangat terlihat jelas. Zonasi Avicennia yang terdepan hasil memiliki 
kelimpahan dan ukuran pohon yang lebih besar dibandingkan dengan jenis yang lain. Jenis Rhizophora sp dan Aegialitis annulata dalam bentuk anakan yang membentuk kawasan tersendiri. Keberadaaan anakan sungai pada stasiun II ini menjadikan jumlah spesies mangrove Rhizophora sedikit lebih besar. Dari hasil penelitian untuk spesies spesies Avicennia sp memiliki jumlah yang paling tinggi, Rhizophora sp, Aegialitis annulata dan Sonneratia sp.

Tabel 1. Hasil Identifikasi mangrove di Kabupaten Merauke

\begin{tabular}{|c|c|c|c|c|}
\hline No & Jenis Mangrove & $\begin{array}{c}\text { Stasiun I } \\
\text { (Distrik } \\
\text { Naukenjerai) } \\
\text { (Nasem) }\end{array}$ & $\begin{array}{l}\text { Stasiun II } \\
\text { (Distrik } \\
\text { Merauke) } \\
\text { (Payum) }\end{array}$ & $\begin{array}{c}\text { Stasiun II } \\
\text { (Distrik } \\
\text { Semangga) } \\
\text { (Kumbe) }\end{array}$ \\
\hline 1 & Avicennia. alba & $\sqrt{ }$ & $\sqrt{ }$ & $\sqrt{ }$ \\
\hline 2 & A. eucalyptifolia & $\sqrt{ }$ & $\sqrt{ }$ & $\sqrt{ }$ \\
\hline 3 & Aegialitis annulata & $\sqrt{ }$ & $\sqrt{ }$ & $\sqrt{ }$ \\
\hline 4 & Aegiceras corniculatum & & $\sqrt{ }$ & \\
\hline 5 & Aegliceras floridum & $\sqrt{ }$ & $\sqrt{ }$ & $\sqrt{ }$ \\
\hline 6 & Acanthus abractearus & & $\sqrt{ }$ & \\
\hline 7 & Brugueira cylindrica & $\sqrt{ }$ & $\sqrt{ }$ & $\sqrt{ }$ \\
\hline 8 & Acanthus ilicifolus & $\sqrt{ }$ & $\sqrt{ }$ & $\sqrt{ }$ \\
\hline 9 & B. gymnorhiza & & & $\sqrt{ }$ \\
\hline 10 & B. hainessii & & & $\sqrt{ }$ \\
\hline 11 & Ceriop decandra & & & $\sqrt{ }$ \\
\hline 12 & Bruguiera sexangula & & & $\sqrt{ }$ \\
\hline 13 & R. mukronata & $\sqrt{ }$ & $\sqrt{ }$ & $\sqrt{ }$ \\
\hline 14 & R. stylosa & & $\sqrt{ }$ & $\sqrt{ }$ \\
\hline \multirow[t]{2}{*}{15} & Sonneratia alba & $\sqrt{ }$ & $\sqrt{ }$ & $\sqrt{ }$ \\
\hline & Jumlah Jenis/ Statsiun & 8 & 11 & 13 \\
\hline
\end{tabular}

Stasiun III Kampung Kumbe yang memiliki luasan mangrove 75,25 ha kondisai yang sangat menarik, selain mangrove yang masih sangat alami, juga kerusakan mangrove yang sangat kecil sekali dibanding dengan dua stasiun yang lain. Secara ekologi mangrove yang terdapat pada stasiun III ini sebagian besar dikelilingi oleh sungai. Menurut Anonym (2013) Sungai Kumbe yang memiliki lebar 100m sangat berpengaruh sekali dengan keanekaragaman dan kelimpahan mangrove. Hasil identifikasi mangrove yang terdapat di Kampung Kumbe didapatkan 13 jenis mangrove dan didominasi oleh jenis Rhizophora sp. Mangrove yang sangat alami dan memiliki ukuran lingkar batang terbesar $194 \mathrm{~cm}$ menjadikan mangrove ini mudah untuk dilakukan identikasi, selain ini pembentukan Zonasi mangrove sangat jelas. Selain Rhizophora $s p$ juga Bruguiera $s p$ yang mendominansi dipesisir Kumbe. Dilihat dari hasil identifikasi stasiun III dibandingkan dengan stasiun yang lain, didapatkan jenis yang paling banyak, hal ini dikarenakan kondisi mangrove yang masih sangat alami atau belum mengalami pengrusakan dan juga memiliki luasan yang tinggi. Untuk jenis Avicennia $s p$ di Pesisir Kumbe lebih kecil dibandingkan dengan Rhizophora sp dikarenakan secara ekologi ekosistem mangrove yang ada di Kampung Kumbu tidak berhadapan langsung dengan laut dan substrat yang kurang sesuai dengan kelangsungan hidup mangrove Avicennia sp.

Secara keseluruhan sebaran mangrove pada tiga Distrik ditemukan jenis Avicennia sp, Rhizophora sp, Sonneratia sp. Ketiga jenis ini merupakan mangrove sejati, dan dikabupaten merauke sangat berpotensi untuk di kembangkan. Selain itu pada ketiga stasiun juga didapatkan jenis Acanthus ilicifolus, jenis mangrove merupakan indikator adanya kerusakan mangrove, jenis ini palin banyak didapatkan pada stasiunII (payum), Kerusakan mangrove pada stasiun II disebabkan karena adanya penambangan pasir secara terus menerus dan pengambilan mangrove untuk bahan bangunan dalam pembuatan rumah. 
3.2. Indeks Nilai Penting Mangrove.

Indek nilai penting (INP) adalah penjumlahan nilai Relatif $\left(R D_{i}\right)$, Frekuensi relatif $\left(R_{i}\right)$ dan Penutupan Relatif $\left(R C_{i}\right)$ dari identifikasi keberadaan ekosistem mangrove. Adapun Nilai masing - masing komponen penyususn Indeks Nilai Penting sebagai berikut:

3.2.1. Indek Nilai Penting pada Distrik Nasem.

Nilai kerapatan jenis merupakan jumlah tegakan jenis ke-i dalam suatu unit area. Adapun kerapatan jenis mangrove di tiga stasiun dapat dilihat pada Tabel 2.

Tabel 2. Nilai Rdi, Rfi, Rci dan INP pada Distrik Nasem

\begin{tabular}{llrrrr}
\hline \multirow{2}{*}{ NO } & \multirow{2}{*}{ Jenis } & \multicolumn{3}{c}{ Stasiun I (NASEM) } & \\
\cline { 3 - 5 } & & \multicolumn{1}{c}{ Rdi } & \multicolumn{1}{c}{ Rfi } & \multicolumn{1}{c}{ Rci } & \multicolumn{1}{c}{ INP } \\
\hline 1 & Avicennia $s p$ & 132 & 87 & 83 & 300 \\
2 & Aegiceras $s p$ & 6,7 & 5,3 & 0,763639 & 15 \\
3 & Brugueira $s p$ & 13,2 & 14,4 & 1,754157 & 41,5 \\
4 & Rhizophora $s p$ & 25 & 29 & 2,100008 & 82 \\
5 & Sonneratia $s p$ & 17 & 11 & 11,4821 & 41,7 \\
\hline
\end{tabular}

Hasil penelitian yang dilakukan di pantai Nasem didapatkan sebanyak 434 pohon, dengan lingkar pohon terbesar $84,1 \mathrm{~cm}$. Dari data yang diperoleh didapatkan nilai kerapatan relatif pada jenis Avicennia sp sebesar Rdi: 132 nilai frekuensi relatif Avicennia $s p$ 87, Nilai Penutupan jenis relatif: 81 sehingga didapatkan nilai INP untuk jenis Avicennia sebesar 300 . Sedangkan nilai INP paling kecil di Kampung Nasem adalah jenis Aegiceras sp, dengan nilai kerapatan Relatif 132, frekuensi relatif 87 dan penutupan relatif 81 .

INP (Indeks Nilai Penting) pohon mangrove jenis Avicennia $s p$ yang diperoleh pada transek 1 dan transek 2. Nilai INP diperoleh dari total penjumlahan kerapatan relatif, penutupan relatif dan frekuensi relatif. Menurut Bengen (2004) nilai penting suatu jenis berkisar antara $0 \%$ dan $300 \%$. Nilai penting ini memberikan suatu gambaran mengenai pengaruh atau peranan suatu jenis tumbuhan mangrove dalam komunitas mangrove. Bila dilihat dari tabel 2 diatas dapat diketahui bahwa INP pada masing-masing transek adalah $300 \%$. Nilai penting ini memberikan gambaran tentang peranan suatu jenis mangrove dalam ekosistem dan juga untuk mengetahui dominansi suatu spesies dalam komunitas. Pada stasiun 1 Avicennia $s p$ sangat dominan, dimana secara ekologi letak pantai Nasem berhadapan langsung dengan laut, subatrat pasir dan lumpur yang dari laut ketika pasang menjadikan mangrove Avicennia $s p$ dapat tumbuh dengan baik. Secara teoritis Zonasi mangrove yang paling depan berhadapan dengan langsung dengan laut adalah Avicennia sp dan Rhizophora sp, dimana pada susbtrat untuk Zonasi paling depan ini, memiliki konsentrasi pasir lebih besar dari pada lumpur. Menurut bangen (2004) untuk kelangsungan hidup mangrove Avicennia sp dan Sonneratia pada zonasi 1 dibutuhkan substrat lumpur berpasir. Selain itu kerusakan mangrove pada Kampung Nasem terjadi pada bagian tengah dari daerah sampling yang disebabkan pengambilan kayu mangrove untuk bangunan jadi kerusakan dari abrasi pantai hampir tidak terjadi.

Hasil penelitian didapatkan jumlah pohon mangrove sebanyak 263 pohon, pohon yang memiliki lingkar pohon terbesar dengan jenis Avicennia sebesar: $68,3 \mathrm{~cm}$. Indek nilai penting pada pesisir payum paling tinggi didapatkan dari jenis Avicennia $s p$ dengan nilai $260 \%$ nilai ini mendekati $300 \%$ yang artinya jensi spesies Avicennia ini Nilai penting ini memberikan suatu gambaran mengenai pengaruh atau peranan suatu jenis tumbuhan mangrove dalam komunitas mangrove yang tinggi. Keberadaan kerapatan Relatif mencapai $83,9001 \%$, frekuensi relatif $66,6667 \%$ dan Luas penutupan relatif $73,35482 \%$ memiliki tingkat dominansi Avicennia yang sangat tinggi dikarenakan secara ekologi pantai payum 
berhadapan langsung dengan laut, kondisi substrat yang mendapatkan input pasir dan

lumpur yang tinggi menjadikan Avicennia sp dapat tumbuh dengan baik.

Tabel 3. Nilai Rdi, Rfi, Rci dan INP pada Distrik Payum

\begin{tabular}{clcccc}
\hline \multirow{2}{*}{ NO } & \multirow{2}{*}{ Jenis } & \multicolumn{3}{c}{ Stasiun II (PAYUM) } & \\
\cline { 3 - 5 } & & Rdi & Rfi & Rci & INP \\
\hline 1 & Avicennia $s p$ & 83,9001 & 66,6667 & 73,35482 & 260 \\
2 & Sonneratia $s p$ & 11,4821 & 20,6271 & 19,35481 & 43 \\
3 & Rhizophora $s p$ & 2,1000 & 5,10123 & 4,83871 & 71 \\
4 & Aegiceras $s p$ & 1,5415 & 6,9655 & 4,03225 & 27 \\
5 & Brugueira $s p$ & 0,76363 & 0,82301 & 0,82301 & 35,8 \\
\hline
\end{tabular}

Tabel 4. Nilai Rdi, Rfi, Rci dan INP pada Distrik Kumbe

\begin{tabular}{cccccc}
\hline \multirow{2}{*}{ NO } & \multirow{2}{*}{ Jenis } & \multicolumn{3}{c}{ Stasiun III (KUMBE) } & \\
\cline { 3 - 5 } & & Rdi & Rfi & Rci & INP \\
\hline \multirow{2}{*}{1} & Rhizophora $s p$ & 67,71653 & 85,4321 & 82,44612 & 235 \\
2 & Brugueira $s p$ & 17,58530 & 11,5679 & 14,24599 & 150 \\
3 & Avicennia $s p$ & 14,60816 & 3,00 & 00,00139 & 18 \\
\hline
\end{tabular}

Pada Tabel 4 diatas menunjukkan INP (Indeks Nilai Penting) pohon mangrove jenis Rhizophora yang diperoleh pada transek 1 sampai 5. Nilai INP diperoleh dari total penjumlahan kerapatan relatif, penutupan relatif dan frekuensi relatif. Hasil Analisis data Indek nilai penting pada Distrik Kumbe terdapat pada jenis Rhizophora $s p$ dengan nilai 235\% dimana nilai ini masuk dalam kategori tinggi. Sedangkan pada jenis Brugueira sp $150 \%$ masuk dalam kategori sedang dan Avicennia sp 18\% yang masuk dalam dalam kategori rendah. Nilai penting ini memberikan suatu gambaran mengenai pengaruh atau peranan suatu jenis tumbuhan mangrove dalam komunitas mangrove yang tinggi arinya pada jenis Rhizophora sp memiliki pengaruh dan peranan yang tinggi pada komunitas mangrove yang ada di Kampung Kumbe. Menurut Bengen (2004) nilai penting suatu jenis berkisar antara $0 \%$ dan $300 \%$. Nilai penting ini memberikan suatu gambaran mengenai pengaruh atau peranan suatu jenis tumbuhan mangrove dalam komunitas mangrove. Besarnya nilai INP yang dimiliki oleh Rhizopora menunjukkan bahwa jenis inilah yang mampu hidup dan berkembang dengan baik di kawasan pengamatan stasiun I. Rhizophora merupakan jenis mangrove yang paling umum di jumpai karena memiliki penyebaran yang luas
Jenis tersebut dapat hidup dengan baik pada daerah yang memiliki pergerakkan air minimal dan tidak dipengaruhi gelombang dan sedimennya berupa lumpur tebal. Kondisi ini sesuai dengan hasil pengamatan di lapangan, dimana pada stasiun I mempunyai substrat berupa lumpur tebal. Berdasarkan zonasi kawasan mangrove, jenis Rhizophora merupakan jenis yang dapat ditemui pada daerah yang dekat dengan daratan (intertidal) yang dicirikan oleh lumpur yang dalam dan kaya bahan organik. Untuk mendapatkan oksigen dari lingkungan yang berlumpur tebal dan kaya bahan organik, jenis ini mempunyai pola adaptasi pada akarnya, yaitu akar tongkat yang dilengkapi oleh lensisel.

\section{PENUTUP}

\subsection{Kesimpulan}

Kesimpulan dari penelitian kondisi dan indeks nilai penting mangrove di Kabupaten Merauke antara lain:

1. Hasil idenifikasi mangrove di Distrik Naukenjerai didapatkan jumlah jenis mangrove 8 jenis mangrove yang dengan jenis mangrove Avicennia sp lebih dominan , Distrik payum 11 jenis mangrove dengan jenis Avicennia sp lebih dominan sedangkan Distrik Kumbe didapatkan 13 jenis mangrove dengan jenis mangrove 
Rhizophora sp lebih melimpah daripada yang lain.

2. Hasil Analisis Indek nilai penting mangrove pada stasiun I Kampung Nasem berkisar antara $300 \%$ - 15\% masuk dalam kategori tinggi. Pada Stasiun II Distrik Payum nilai INP berkisar antara $260 \%-27 \%$ memiliki nilai kategori tinggi sedangkan untuk stasiun III Distrik Kumbe nilai INP berkisar antara235\% - 18\%. Juga masuk kategori INP tinggi.

\subsection{Saran}

1. Perlu dilakukanya penelitian tentang ekologi mangrove di Kabupaten Merauke

2. Perlu dilakukannya penelitian tentang karakteristik pertumbuhan mangrove di Kabupaten Merauke

\section{DAFTAR PUSTAKA}

Anonim, 2011. Badan Pusat Statistik, Kabupaten Merauke In Figures. Kabupaten Merauke.

Anonim, 2009. Laporan Tahunan Dinas Kelautan dan Perikanan Kabupaten Merauke

Anonim, 2006. Buku 1 Potret Sumberdaya Kawasan Laut Arafura dan Laut Timor Menuju Pembangunan Berkelanjutan. Forum Pakar Laut Arafura dan Laut Timor.

Bengen, D. G. 2004. Pedoman teknis: Pengenalan dan pengelolaan ekosistem mangrove. PKSPLIPB. Bogor.

Bengen. D. G. dan I. M. Dutton 2004. Interaction: mangroves, fisheries and forestry management in Indonesia. H. 632-653. Dalam Northcote. T. G. dan Hartman (Ed),Worldwide watershed interaction and management. Blackwell science.. Oxford. UK.)

Hartini, S., G. B. Saputro, M. Yulianto, Suprajaka. 2010. Assessing the Used of Remotely Sensed Data for Mapping Mangroves Indonesia. Selected Topics in Power Systems and Remote Sensing. In 6th Wseas International Conference on Remote Sensing (Remote'10), Iwate Prefectural University, Japan. October 4-6, 2010; pp. 210-215

Masiya siti, 2014. Komposisi jenis dan kerapatan Mangrove di Pesisir Arafura Kabupaten Merauke Provinsi Papua. Jurnal Agrikan Volume 8 Edisi 1, Mei 2015.

Nontji. (2007). Laut Nusantara. Penerbit Djambatan- Jakarta.

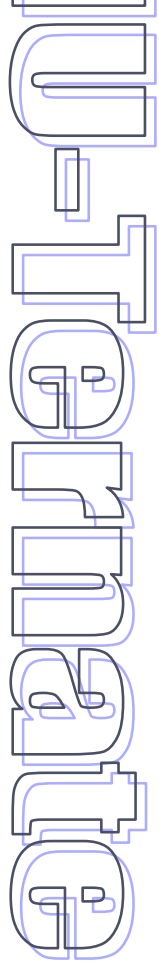

